\title{
Reallocating Liquidity to Resolve a Crisis: Evidence from the Panic of $1873^{*}$
}

\author{
Haelim Anderson \\ Federal Deposit Insurance Corporation \\ Kinda Hachem \\ University of Virginia and NBER \\ Simpson Zhang \\ Office of the Comptroller of the Currency
}

\begin{abstract}
In environments where aggregate liquidity is insufficient, the prevention of bank failures requires either a liquidity injection by the central bank or a suspension of convertibility. Suspensions lock savers out of their funds, undermining the liquidity service that banks exist to provide. At the same time, post-crisis reforms are deliberately curtailing the ability of central banks to create new, stigma-free lending facilities that inject emergency liquidity, especially for shadow banks. This raises a critical question: Can anything be done to mitigate bank failures when neither a suspension of convertibility nor a liquidity injection by the central bank is viable? In this paper, we show that there is a forced reallocation of existing liquidity that achieves fewer bank failures than a decentralized interbank market. We also show that this reallocation can be implemented through the issuance of centralized loan certificates, which were a policy instrument utilized by the New York Clearinghouse (NYCH) during the Panic of 1873. Using a novel, hand-collected data set, we find that the NYCH issued loan certificates to banks in the way our model suggests they should have, helping to resolve the panic. We also consider alternative policies in a quantitative extension and find that none do uniformly better than loan certificates.
\end{abstract}

\footnotetext{
* The views expressed in this paper are those of the authors and do not necessarily represent the views of the Office of the Comptroller of the Currency, the U.S. Department of the Treasury, or the Federal Deposit Insurance Corporation. The authors are responsible for any errors.
} 